\title{
Acessibilidade e tecnologia assistiva em bibliotecas universitárias: estudo de caso no Centro Federal de Educação Tecnológica de Minas Gerais
}

\author{
Katia Gonçalves dos Santos \\ Centro Federal de Educação Tecnológica de Minas Gerais, Belo Horizonte, MG, Brasil \\ katiasantosbiblio@yahoo.com.br \\ Keila Auxiliadora de Carvalho \\ Universidade Federal dos Vales do Jequitinhonha e Mucuri, Diamantina, MG, Brasil \\ keilaaauxiliadora@gmail.com
}

DOI: https://doi.org/10.26512/rici.v13.n1.2020.22362

Recebido/Recibido/Received: 2019-01-29

Aceitado/Aceptado/Accepted: 2019-09-24

Resumo: O presente artigo discute os resultados de uma pesquisa que analisou as condições de acessibilidade e o uso de tecnologia assistiva no Sistema de Bibliotecas (SIBI) do Centro Federal de Educação Tecnológica de Minas Gerais (CEFET-MG). O estudo teve como objetivo investigar a aplicação das políticas públicas de inclusão no SIBI do CEFET-MG. Para realização do estudo, foram utilizadas três técnicas de coleta de dados: a observação realizada em duas bibliotecas do SIBI; questionários enviados através do Google docs para os bibliotecários coordenadores do SIBI; e entrevistas semiestruturadas para três alunos(as) com necessidades educacionais especiais. Os resultados mostram avanços como: o recebimento de alunos(as) com necessidades educacionais especiais na instituição de ensino analisada; a construção ou adaptação de prédios acessíveis; o fornecimento de tecnologias para auxiliar os estudantes com alguma necessidade educacional especial nos estudos; e o acolhimento pela maior parte da comunidade acadêmica. No entanto, constatou-se também a necessidade de articulação intersetorial, treinamento de servidores e melhora nas condições de acessibilidade e tecnologia assistiva.

Palavras-chave: Políticas Públicas. Inclusão. Acessibilidade. Tecnologia Assistiva. Pessoas com necessidades educacionais especiais.

Accessibility and assistive technology in university libraries: case study in Federal Center of Technological Education of Minas Gerais

Abstract: The present article discusses the results of a research that analyzed the accessibility conditions and the use of assistive technology in the System of Libraries (SIBI) of the Federal Center of Technological Education of Minas Gerais (CEFET-MG). The objective of this study was to investigate the application of the public policies of inclusion in the SIBI of CEFET-MG. For the accomplishment of the study, three techniques of data collection were used: the observation realized in two libraries of the SIBI; questionnaires sent through Google docs to SIBI coordinators librarians; and semi-structured interviews for three students with special educational needs. The results show advances such as: the receipt of students with special educational needs in the analyzed educational institution; the construction or adaptation of affordable buildings; the provision of technologies to assist students with some special educational need in their studies; and the acceptance by most of the academic community. However, there was also the need for intersectoral articulation, training of servers and improvement in the conditions of accessibility and assistive technology.

Keywords: Public Policies. Inclusion. Accessibility. Assistive Technology. People with special educational needs. 
Accesibilidad y tecnología asistida en bibliotecas universitarias: estudio de caso en el Centro Federal de Educación Tecnológica de Minas Gerais

Resumen: El presente artículo discute los resultados de una investigación que analizó las condiciones de accesibilidad y el uso de tecnología asistida en el Sistema de Bibliotecas (SIBI) del Centro Federal de Educación Tecnológica de Minas Gerais (CEFET-MG). El objetivo de este estudio fue investigar la aplicación de las políticas públicas de inclusión en el SIBI de CEFET-MG. Para la realización del estudio, se utilizaron tres técnicas de recolección de datos: la observación realizada en dos bibliotecas del SIBI; cuestionarios enviados a través de Google docs para los bibliotecarios jefes del SIBI; y entrevistas semiestructuradas para tres alumnos con necesidades educativas especiales. Los resultados muestran avances como: la recepción de alumnos con necesidades educativas especiales en la institución de enseñanza analizada; la construcción o adaptación de edificios accesibles; el suministro de tecnologías para ayudar a los estudiantes con alguna necesidad educativa especial en los estudios; y la acogida por la mayor parte de la comunidad académica. Sin embargo, se constató también la necesidad de articulación intersectorial, entrenamiento de servidores y mejora en las condiciones de accesibilidad y tecnología asistida.

Palabras clave: Políticas Públicas. Inclusión. Accesibilidad. Tecnología Asistida. Personas con necesidades educativas especiales.

\section{Introdução}

O recebimento de alunos com deficiência, transtornos globais do desenvolvimento, altas habilidades ou superdotação ${ }^{1}$ preferencialmente nas classes comuns do ensino regular consiste em uma política recente iniciada com as reformas educacionais da década de 1990.

No Brasil, a partir de 2003, o governo federal passou a optar pela matrícula do público da educação especial preferencialmente nas classes comuns do ensino regular (KASSAR, 2011). Sendo assim, em 2016, a matrícula de alunos(as) com necessidades educacionais especiais (NEE) nas classes comuns, ultrapassou as matrículas em classes e instituições especiais (CENSO, 2017).

Dessa forma, nos propusemos a investigar os desdobramentos práticos das políticas de inclusão, através da análise dos serviços oferecidos para o público da educação especial, nas bibliotecas de uma instituição de ensino técnico e superior. Para isso, analisamos dois aspectos fundamentais para a inclusão: a acessibilidade e a tecnologia assistiva.

Entende-se por acessibilidade a construção de produtos, ambientes, programas e serviços de forma a permitir sua utilização por todas as pessoas de maneira autônoma e segura. Já tecnologia assistiva (TA) é um grupo de serviços, produtos e ferramentas desenvolvidos através da tecnologia, para facilitar as atividades no cotidiano das pessoas com necessidades educacionais especiais e garantir-Ihes o máximo possível de autonomia, como exemplo podemos citar a cadeira de rodas, o teclado ampliado, a impressora Braille, o ampliador de tela, dentre outros (BERSCH, 2013; SASSAKI, 2006).

\section{Políticas públicas de inclusão}

\footnotetext{
${ }^{1}$ Público da educação especial, conforme Lei de Diretrizes e Bases da Educação Nacional (LDB) n. 9.394 de 1996.
} 
As políticas públicas de inclusão surgiram junto com as reformas educacionais de 1990 . Duas conferências marcam o desenvolvimento dessas políticas, a Conferência Mundial de Educação para Todos, realizada em 1990, em Jomtien, Tailândia, que prevê a universalização do ensino para todos e a Conferência Mundial sobre Necessidades Educacionais Especiais, promovida em 1994, em Salamanca, Espanha. Dessa última, surgiu a Declaração de Salamanca, que reafirma a necessidade de reformas no sistema de ensino, a fim de incluir pessoas com necessidades educacionais especiais (MENDES, 2006).

No Brasil, a Constituição de 1988, garantiu a universalização e o acesso ao ensino. Em relação aos direitos sociais previstos para as pessoas com deficiência, ficou assegurado o direito à saúde, educação, seguridade social, acessibilidade e proteção. No que se refere à educação, o art. 208, inciso III, garantiu o atendimento educacional especializado, preferencialmente na rede regular de ensino ${ }^{2}$ (BRASIL, 1988).

A Lei de Diretrizes e Bases da Educação Nacional (LDB) n. 9.394 de 1996, reafirma o atendimento educacional especializado preferencialmente na rede regular de ensino, conforme previsto na Constituição (1988). Ela também reconhece a educação especial como modalidade de ensino, e define o público da educação especial, não restringindo apenas as pessoas com deficiência, mais inclui também pessoas com transtornos globais do desenvolvimento e altas habilidades ou superdotação.

No entanto, mesmo após a promulgação da Constituição (1988) e da LDB de 1996, que garantem a educação especial preferencialmente na rede regular de ensino, a maior parte das matrículas para esse público esteve durante a década de 1990, nas escolas e classes especiais (MENDES, 2010).

Apenas em 2003, as matrículas do público da educação especial, em instituições e classes especiais foram substituídas por classes comuns no ensino regular (KASSAR, 2011). No segundo mandato do governo Lula, iniciou-se também o processo de substituição da Política Nacional de Educação Especial, Política Nacional para a Integração da Pessoa Portadora de Deficiência e as Diretrizes Nacionais para a Educação Especial, pela Política Nacional de Educação Especial na Perspectiva da Educação Inclusiva (2008) (PADILHA, 2014).

\footnotetext{
${ }^{2}$ Em interpretação do Ministério Público Federal (MPF), o atendimento educacional especializado não pode em hipótese alguma substituir a educação, sendo essa oferecida, de acordo com a Constituição (1988), somente na instituição escola. Sendo assim, o atendimento educacional especializado constituise de um complemento, podendo ou não ser oferecido na rede regular de ensino, no entanto, a educação deve obrigatoriamente ser oferecida na rede regular de ensino para todas as pessoas, independente de possuírem ou não alguma necessidade educacional especial (BRASIL, 2004b).
} 
A Política Nacional de Educação Especial na Perspectiva da Educação Inclusiva foi elaborada em 2008, e entregue ao Ministério da Educação (MEC) pelo grupo de trabalho nomeado pela Portaria no 555/2007, prorrogada pela Portaria no 948/2007. De acordo com esse documento, essa política tem por objetivo:

[...] assegurar a inclusão escolar de alunos com deficiência, transtornos globais do desenvolvimento e altas habilidades/superdotação, orientando os sistemas de ensino para garantir: acesso ao ensino regular, com participação, aprendizagem e continuidade nos níveis mais elevados do ensino; transversalidade da modalidade de educação especial desde a educação infantil até a educação superior; oferta do atendimento educacional especializado; formação de professores para o atendimento educacional especializado e demais profissionais da educação para a inclusão; participação da família e da comunidade; acessibilidade arquitetônica, nos transportes, nos mobiliários, nas comunicações e informação; e articulação intersetorial na implementação das políticas públicas (BRASIL, 2008; online).

Para assegurar essa política, foram desenvolvidos programas como: Salas de Recursos Multifuncionais; "Olhar Brasil"; e Programa de Acompanhamento e Monitoramento do Acesso e Permanência das Pessoas com Deficiência subvencionadas pelo Benefício de Prestação Continuada; Programa Incluir, esse último com o objetivo de criar e consolidar núcleos de acessibilidade nas instituições federais de ensino (PADILHA, 2014). Nesse período, o número de matrículas desse público, começou a aumentar progressivamente nas classes comuns do ensino regular.

Devido a substituição progressiva das políticas para a educação especial, em 2016, o número de matrículas da educação especial nas classes comuns da rede regular, excedeu as instituições e classes especiais (INEP. Censo, 2017). Concretizando assim, em parte, o proposto pelas reformas educacionais da década de 1990.

Em 28 de dezembro de 2016, foi sancionada a Lei n. 13.409, que altera a Lei n. 12.711, de 29 de agosto de 2012. Essa lei garante a reserva de vagas para pessoas com deficiência nos cursos técnicos de nível médio e superior das instituições federais de ensino. No mesmo período, foi aprovada a Emenda constitucional (EC) 95, de 2016, que prevê o congelamento de investimentos por vinte anos, inclusive, para a Saúde e a Educação. Sendo assim, constatamos que, por um lado mantém-se o arcabouço legal sobre a inclusão, por outro, inviabiliza o desenvolvimento da mesma, devido à falta de recursos (MUSTAFA, 2019).

Atualmente, a educação especial do país, vivencia um quadro de superação do número de matrículas em escolas comuns do ensino regular, em relação às classes e escolas especiais. No entanto, a inclusão dessas pessoas esbarra com o número ainda grande desse público fora 
de qualquer escola ${ }^{3}$, além dos problemas enfrentados pelo sistema de ensino brasileiro. Dessa forma, o desafio consiste, como bem coloca Mendes (2010, p. 106-107), em "construir uma escola brasileira pública de melhor qualidade para todos, e ao mesmo tempo, garantir que as especificidades da população alvo da educação especial sejam respeitadas". Acreditamos que mudanças tão profundas na educação brasileira somente serão possíveis através de uma profunda mudança social no país.

\section{Acessibilidade em bibliotecas universitárias}

O processo de inclusão de alunos(as) com necessidades educacionais especiais nas instituições de ensino regular do país, tem provocado uma necessidade de mudança nessas instituições para receber esses(as) alunos(as). Essas mudanças vão além das salas de aula, expandindo-se por toda a instituição de ensino. Nesse sentido, entendemos as bibliotecas como parte do processo de desenvolvimento acadêmico do estudante, facilitando e promovendo o acesso à informação e ao conhecimento.

Os ambientes educacionais, em especial os universitários, estão associados à produção e disseminação do conhecimento. Este processo é inerente ao meio acadêmico, influenciando na qualidade da própria educação. Dessa forma, as pessoas são agentes da informação, são elas quem a produzem e acessam. Para que todas as pessoas estejam incluídas nesse processo, a informação precisa ser acessível, sendo a biblioteca parte fundamental desse processo (MAZZONI et al., 2001). Nessa linha de pensamento Fialho e Silva (2012), argumentam que:

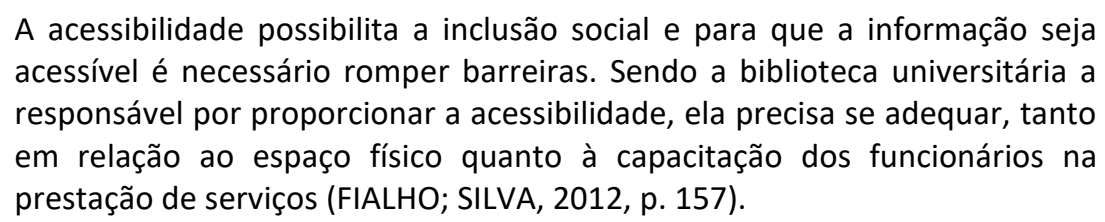

Para garantir que todas as pessoas possam ir ao encontro da informação, a biblioteca precisa ser acessível, garantindo condições de acesso físico e oferecendo serviços diferenciados, fazendo uso de tecnologias que possibilitem as pessoas com necessidades educacionais especiais, acessarem a informação independente de sua necessidade especial. Sendo assim, é necessário que a biblioteca:

[...] acolha um maior número de pessoas em suas atividades, que tenha instalações adequadas para atender cada um, conforme suas diferenças físicas, antropométricas e sensoriais; somando-se a isso a acessibilidade digital e tecnológica de forma organizada. Além disso, os funcionários devem ser solícitos no momento do atendimento, permitindo a acessibilidade. A

\footnotetext{
${ }^{3}$ http://agenciabrasil.ebc.com.br/educacao/noticia/2014-09/falhas-da-educacao-inclusiva-aindadeixam-140-mil-jovens-fora-das-escolas.
} 
parte arquitetônica e os produtos são fundamentais para um planejamento de biblioteca que seja acessível (FIALHO; SILVA, 2012, p. 155).

Malheiros (2013) ressalta o papel fundamental das bibliotecas universitárias no auxílio e permanência dos alunos(as), fornecendo a informação adaptada e necessária ao seu desenvolvimento acadêmico. Destaca também a importância das bibliotecas digitais na disponibilização da informação na internet.

Para Pupo (2006), é importante ressaltar os avanços em Ciência e Tecnologia e o desenvolvimento das novas tecnologias da informação e comunicação. De acordo com a autora, esses acontecimentos "contribuíram significativamente, ampliando as possibilidades de acesso de pessoas com deficiência à web e, consequentemente, ao conhecimento" (PUPO, 2006, p. 41). Na mesma linha de pensamento, Sonza (2008) afirma que:

O crescente desenvolvimento das tecnologias da informação vem contribuindo para a democratização da utilização dos espaços virtuais. Essa disseminação tem possibilitado: apoiar processos educativos mais interativos, otimizar um uso mais reflexivo para a informação, a comunicação e as trocas sociocognitivas entre usuários, oferecer alternativas àqueles que possuem dificuldades de horários e deslocamento e viabilizar a construção de respostas positivas às especificidades de cada usuário (SONZA, 2008, p. 21).

A inserção de pessoas com necessidades educacionais especiais nas instituições de ensino, desperta para um novo olhar sobre a diversidade humana e o direito de todos a educação. Nessa perspectiva, a biblioteca universitária tem papel fundamental, sendo ela a responsável pelo acesso e democratização da informação (PUPO; MARTINS, 2014).

\section{Tecnologia assistiva como instrumento de inclusão}

Para garantir a inclusão de pessoas com necessidades educacionais especiais, tem sido necessário ligar as múltiplas dimensões da acessibilidade com a tecnologia assistiva. A TA referese a um conjunto de serviços, produtos e ferramentas desenvolvidos através da tecnologia, para facilitar as atividades no cotidiano das pessoas com alguma limitação física, sensorial ou intelectual, e garantir a essas o máximo possível de autonomia.

De acordo com a Ata VII do Comitê de Ajudas Técnicas, a tecnologia assistiva pode ser entendida como:

[...] uma área do conhecimento, de característica interdisciplinar, que engloba produtos, recursos, metodologias, estratégias, práticas e serviços que objetivam promover a funcionalidade, relacionada à atividade e participação, de pessoas com deficiência, incapacidades ou mobilidade reduzida, visando sua autonomia, independência, qualidade de vida e inclusão social (BRASIL, 2007, p. 3).

Para Melo, Costa e Soares (2006), as TA "são recursos e serviços que visam facilitar o desenvolvimento de atividades da vida diária por pessoas com deficiência. Procuram aumentar 
capacidades funcionais e assim promover a autonomia e a independência de quem as utiliza" (Ibid., p. 62).

Segundo Bersch o "objetivo maior da tecnologia assistiva é proporcionar à pessoa com deficiência maior independência, qualidade de vida e inclusão social, através da ampliação de sua comunicação, mobilidade, controle de seu ambiente, habilidades de seu aprendizado e trabalho" (BERSCH, 2013, p. 2).

A política de educação inclusiva tem sido responsável pela introdução da TA no ambiente escolar. Visando diminuir as barreiras para promover a inclusão de alunos(as) com necessidades educacionais especiais, a TA favorece na autonomia desses estudantes. Trata-se de uma área abrangente, podendo ser um material, produto ou serviço. No contexto educacional uma tecnologia pode ser considerada assistiva quando:

[...] ela é utilizada por um aluno com deficiência e tem por objetivo romper barreiras sensoriais, motoras ou cognitivas que limitam/impedem seu acesso às informações ou limitam/impedem o registro e expressão sobre os conhecimentos adquiridos por ele; quando favorecem seu acesso e participação ativa e autônoma em projetos pedagógicos; quando possibilitam a manipulação de objetos de estudos; quando percebemos que sem este recurso tecnológico a participação ativa do aluno no desafio de aprendizagem seria restrito ou inexistente (BERSCH, 2013, p. 12).

Sobre o uso da TA na educação, Conte, Ourique e Basegio (2017, p. 20), argumentam que:

É preciso considerar que a questão da TA na escola cria condições para o estabelecimento de novos padrões sociais de interação, possibilitando aos sujeitos com deficiências se desenvolverem e exercitarem sua condição humana no convívio com o outro, através de processos de sensibilização, inclusão, reconhecimento e cidadania.

Em relação à utilização de TA nas bibliotecas, com o objetivo de permitir maior autonomia para as pessoas com necessidades educacionais especiais, encontramos as mais diversas, servindo na locomoção, acesso à informação e na comunicação. Dentre essas, Melo, Costa e Soares (2006) citam: cadeiras de rodas, bengalas, órteses e próteses, lupas, aparelhos auditivos, teclados alternativos, ponteiras de cabeça, sistemas para entrada de voz (speech recognition), ampliadores de tela, leitores de tela com síntese de voz, linhas Braille, impressoras Braille, software especializados para produção de material em Braille, leitores de telas como o Virtual Vision, o Jaws, e o Dosvox, dentre outras.

Também em Oliveira (2013), encontramos alguns recursos que podem ser incorporados nas bibliotecas com o objetivo de garantir a autonomia de pessoas com necessidades educacionais especiais:

Equipamentos de auxílio à mobilidade: o Stair Track e o Evacu-Trac. Enquanto o Stair-Trac pode ser acoplado a uma cadeira de rodas para auxiliar a subir e 
descer escadas, o Evacu-Trac foi desenhado para auxiliar na mobilidade de pessoas com dificuldades de locomoção.

Ampliadores de telas: ampliam e modificam as cores da tela, visando melhorar a leitura de textos e a percepção de imagens, para pessoas com dificuldades de enxergar, exemplo: lentes de aumento.

Leitores de tela: lêem informações textuais por meio de sintetizadores de voz ou displays em Braille, para pessoas cegas ou com dificuldade de leitura, exemplos: Virtual Vision, Monitivox, Jaws.

Programas de reconhecimento de voz: possibilitam o acionamento de comandos dos programas via voz e podem ser usados por quem tem deficiência que dificulte, ou impeça o uso de teclado ou mouse, por exemplo.

Teclados alternativos: simulam o funcionamento de um teclado normal, logo ajudando as pessoas que tenham alguma dificuldade ou impossibilidade de utilizar o teclado.

Dispositivos apontadores alternativos: simulam o funcionamento do mouse e assim podem ser utilizados por quem não possa utilizar o mouse convencional, exemplos são aqueles que são acionados com os olhos (eye gaze systems) ou com os pés (FONSECA; PINTO, 2009 apud OLIVEIRA, 2013, p. 29-30).

Percebemos que essas ideias convergem com o previsto na ABNT NBR 15599 de 2008, que prevê o uso e disponibilidade de TA nas escolas, bibliotecas e espaços educativos:

Escolas, bibliotecas e demais espaços educativos devem prover equipamentos e programas de computador com interfaces específicas, como ampliadores de tela, sintetizadores de voz, impressoras e conversores braille, entre outras possibilidades (ABNT NBR 15599, 2008, p. 9).

Entendemos que a disposição de TA nas bibliotecas das instituições de ensino, garantem autonomia e independência na busca pela informação. Possibilitando a democratização do acervo para todas as pessoas, ao mesmo tempo em que cumpre as legislações brasileiras voltadas para a inclusão de pessoas com necessidades educacionais especiais.

\section{Metodologia e caracterização da amostra}

As análises das condições de acessibilidade e do uso de tecnologia assistiva no SIBI do CEFET-MG, apresentadas nesse artigo, são fragmento de uma pesquisa de mestrado. Por se tratar de um estudo contemporâneo e de uma pesquisa empírica de abordagem qualitativa, optamos pelo estudo de caso.

Na condução do estudo, utilizamos três técnicas de coleta de dados: observação em duas bibliotecas do SIBI, uma na capital e a outra no interior; questionários aplicados aos/as bibliotecários(as) coordenadores(as) de cada biblioteca do SIBI; E entrevista semiestruturada com dois/duas alunos(as) e um/uma ex-aluno(a) do CEFET-MG com necessidades educacionais 
especiais. Para garantir o sigilo, optamos por não identificar o sexo de nenhum dos sujeitos envolvidos.

A observação levou em consideração a ABNT NBR 9050 de 2015, acessibilidade a edificações, mobiliário, espaços e equipamentos urbanos, e a ABNT NBR 15599 de 2008, acessibilidade - comunicação na prestação de serviços.

Em relação aos/as bibliotecários(as) coordenadores(as) das bibliotecas, foram enviados 10 questionários, dos quais foram respondidos 09. Sobre os/as alunos(as) com necessidades educacionais especiais, foram selecionados, um/uma aluno(a) do técnico, um/uma da graduação e um/uma da pós-graduação. Os/As mesmos(as) apresentam deficiência física, auditiva e visual, possibilitando assim uma visão mais ampliada sobre as necessidades de serviços nas bibliotecas em questão.

A análise dos questionários e entrevistas foi realizada a partir da elaboração de categorias. Essas categorias foram escolhidas, levando em consideração a comunicação intersetorial, a acessibilidade, a tecnologia assistiva, os serviços oferecidos para alunos(as) com NEE, e a educação inclusiva. Acreditamos que esses tópicos, contemplam os anseios que permeiam as discussões em torno da inclusão.

\section{Apresentação das condições de acessibilidade e tecnologia assistiva no SIBI do CEFET MG}

Nessa seção apresentamos os aspectos analisados na observação, questionário e entrevistas, bem como seus respectivos resultados.

\subsection{Os espaços das bibliotecas}

Por meio da observação foi possível perceber a acessibilidade parcial das bibliotecas observadas. Em muitos aspectos, elas oferecerem acessibilidade, com estacionamento reservado, rampas e piso tátil em seu entorno, banheiro reservado, distância adequada entre as estantes, presteza dos servidores no atendimento, balcões de atendimento e bebedouros acessíveis. Contudo, encontramos também barreiras causadas pela falta de espaço, móveis dispostos no corredor, rampas com inclinação inadequada e a falta de materiais em formatos acessíveis.

\subsection{A percepção dos(as) alunos(as) com necessidades educacionais especiais e dos(as)}

\section{bibliotecários(as) acerca da inclusão no SIBI do CEFET-MG}

Com o objetivo de entender as percepções dos(as) alunos(as) com necessidades educacionais especiais e $\operatorname{dos}(a s)$ bibliotecários(as) do CEFET-MG acerca da inclusão nas bibliotecas da instituição, foram realizadas duas formas distintas de coleta de dados com esses 
dois seguimentos: questionário para os/as bibliotecários(as) coordenadores(as) do SIBI, entrevista semiestruturada para dois/duas alunos(as) e um/uma ex aluno(a) do CEFET-MG. Os aspectos abordados nos questionários e entrevistas serão descritos a seguir:

\subsubsection{Matrícula de Alunos(as) com NEE}

A análise dessa categoria mostrou que falta uma articulação intersetorial na instituição, a fim de desenvolver as políticas públicas de inclusão. Os/As alunos(as) com necessidades educacionais especiais, não tem sido identificados com rigor durante a entrada na instituição. Ao mesmo tempo em que as informações referentes a esses/essas alunos(as) não tem sido repassadas para as bibliotecas, visando proporcionar um melhor atendimento para esses estudantes.

\subsubsection{Núcleo de Atendimento às Pessoas com Necessidades Educacionais Específicas do CEFET-} MG

Verificamos nessa categoria, que falta uma maior interação entre o Núcleo de Atendimento às Pessoas com Necessidades Educacionais Específicas (NAPNE) e os/as alunos(as) com necessidades educacionais especiais, bem como, entre o NAPNE e o SIBI do CEFET-MG. Sendo de extrema importância para o desenvolvimento da educação inclusiva, a estruturação desse núcleo.

\subsubsection{Tecnologia Assistiva no SIBI do CEFET-MG}

Constatamos a importância da disponibilização de TA para autonomia e independência de alunos(as) com NEE. Através da pesquisa foi possível perceber que, em parte, as tecnologias assistivas vêm sendo fornecidas pela instituição analisada. A respeito das bibliotecas fica evidente a precariedade nesse campo, tanto em relação à disposição de TA para possibilitar a inclusão dos(as) alunos(as) com NEEs, quanto ao conhecimento dos(as) bibliotecários(as) sobre essas tecnologias. Sendo assim, percebemos um confronto entre o discurso legal e as práticas de inclusão.

\subsubsection{Acessibilidade no Sistema de Bibliotecas do CEFET-MG}

Nessa categoria, analisamos as percepções dos(as) participantes sobre as seis dimensões da acessibilidade: arquitetônica (sem barreiras ambientais físicas), comunicacional (sem barreiras na comunicação interpessoal), metodológica (sem barreiras nos métodos e técnicas de estudo), instrumental (sem barreiras nos instrumentos, equipamentos de estudo), 
programática (sem barreiras invisíveis embutidas em políticas como leis, decretos, portarias, resoluções etc.) e atitudinal (sem preconceitos, estigmas, estereótipos e discriminações).

Em relação a acessibilidade arquitetônica, os resultados mostram que essa acessibilidade tem sido garantida através da construção e adaptação de prédios acessíveis, conforme previsto na legislação. No entanto, a pesquisa apontou a presença de algumas barreiras como espaços inadequados (grande quantidade de móveis e pessoas para um espaço pequeno), rampas com inclinação inadequada, ausência de piso tátil nas bibliotecas observadas

No que diz respeito à acessibilidade comunicacional, constatamos problemas no oferecimento dessa acessibilidade, como a falta de utilização de mensagens alternativas, bem como, a falta de treinamento dos servidores, em especial para comunicação em libras.

Os problemas na oferta da acessibilidade metodológica, estão relacionados à falta de disposição de TA para os/as alunos(as) com NEE e a necessidade de desenvolvimento do NAPNE para um efetivo atendimento educacional especializado.

A acessibilidade instrumental tem uma ligação direta com a TA, sendo assim, o não oferecimento de TA para os/as alunos(as) com NEE, e a falta delas nas bibliotecas analisadas, impedem essa acessibilidade.

Sobre a acessibilidade programática, a maioria dos participantes acredita possuir essa acessibilidade na instituição analisada. Consideramos que a afirmativa acerca dessa acessibilidade, esteja ligada a existência de arcabouço legal, voltado para o acesso e permanência de pessoas com NEE na rede regular de ensino.

No que se refere à acessibilidade atitudinal, embora tenha sido relatado um caso de preconceito, a maior parte dos participantes acredita na existência dessa acessibilidade na instituição de ensino analisada. Acreditamos que, isso se deva ao desenvolvimento de um discurso social a favor da inclusão de pessoas com NEE.

O estudo possibilitou perceber avanços na acessibilidade arquitetônica, programática e atitudinal que se referem à acessibilidade nos espaços físicos, legislações e a atitude não discriminatória das pessoas. No entanto, foi constatado a necessidade de desenvolver a acessibilidade comunicacional, metodológica e instrumental, relacionadas com o treinamento de servidores e a utilização de TA.

\subsubsection{Serviços de Informação para Pessoas com NEE no SIBI do CEFET-MG}

Através das respostas foi possível perceber a importância da biblioteca para a democratização do acesso à informação na instituição de ensino analisada. Para que esse acesso seja garantido aos/as alunos(as) com NEE, faz-se necessário um ambiente adequado, que seja acessível, com TA e profissionais capacitados. 
Em relação ao atendimento as pessoas com NEE, a pesquisa aponta para as dificuldades decorrentes da falta de treinamento dos(as) servidores(as), falta de estruturação do NAPNE, precariedade no oferecimento de TA e acessibilidade.

\subsubsection{A Prática da Inclusão no SIBI do CEFET-MG}

Todos(as) os/as alunos(as) com necessidades educacionais especiais, se sentem incluídos. Embora existam problemas na inclusão, o fato de serem acolhidos pela comunidade acadêmica, incluindo o tratamento oferecido pelos servidores da biblioteca, faz com que se sintam incluídos. Comprovando assim, a importância da afetividade no processo de inclusão. Em relação aos/as bibliotecários(as), suas respostas sinalizam para a importância de se desenvolver a acessibilidade e a tecnologia assistiva, visando assim o desenvolvimento da educação inclusiva no CEFET-MG.

\section{Considerações finais}

Após a Conferência Mundial de Educação para Todos e a Conferência Mundial sobre Necessidades Educacionais Especiais, o Brasil passou a adotar políticas públicas de educação para todos e de educação inclusiva (MENDES, 2010). Essa lógica, envolta pelo discurso da inclusão, embasou as mudanças nas políticas educacionais brasileiras para a educação especial, aumentando consideravelmente o número de alunos(as) com NEE nas classes comuns do ensino regular.

Através da pesquisa foi possível identificar alguns avanços, como: o recebimento de alunos(as) com necessidades educacionais especiais na instituição de ensino analisada; a construção ou adaptação de prédios acessíveis; o fornecimento de tecnologias para auxiliar os estudantes com alguma necessidade educacional especial nos estudos; e o acolhimento pela maior parte da comunidade acadêmica. Importante destacar que, em nenhuma resposta, os(as) bibliotecários(as) estigmatizaram os alunos com NEE, pelo contrário, deixaram claro que o ambiente é que deve ser modificado para melhor atendê-los.

No entanto, as reflexões $\operatorname{dos}($ as) participantes, mostram uma contradição entre as políticas públicas de inclusão, e a prática da inclusão na instituição de ensino analisada. As barreiras relatadas comprometem o direito a inclusão. Sendo assim, entendemos que a garantia do direito a educação especial na rede regular de ensino presentes na legislação, não garantem por si só a inclusão desses estudantes.

Entendemos que o CEFET-MG, precisa ultrapassar o campo do discurso e aplicar de forma integral o previsto na legislação. Para que isso ocorra, faz-se necessário desenvolver o 
NAPNE, investir na informação/comunicação intersetorial, oferecer treinamento/capacitação para os servidores, e garantir condições de acessibilidade e TA. Compreendemos também, que esse desenvolvimento esbarra com um progressivo corte de verbas na educação pública do país.

\section{Referências}

ASSOCIAÇÃO BRASILEIRA DE NORMAS TÉCNICAS (ABNT). NBR 9050: acessibilidade a edificações, mobiliário, espaços e equipamentos urbanos. 3. ed. Rio de Janeiro, 2015.

ASSOCIAÇÃO BRASILEIRA DE NORMAS TÉCNICAS (ABNT). NBR 15599: acessibilidade comunicação na prestação de serviços. Rio de Janeiro, 2008.

BERSCH, Rita. Tecnologia assistiva. Porto Alegre: Edição do Autor, 2013. Disponível em: <http://www.assistiva.com.br/Introducao_Tecnologia_Assistiva.pdf >. Acesso em: 3 ago. 2016.

BRASIL. CORDE. Ata VII reunião do Comitê de Ajudas Técnicas. Brasília, 2007. Disponível em: <http://www.assistiva.com.br/Ata_VII_Reuni\%C3\%A3o_do_Comite_de_Ajudas_T\%C3\%A9cnic as.pdf >. Acesso em: 24 set. 2019.

BRASIL. Constituição (1988). Constituição da República Federativa do Brasil. Brasília, DF: Senado Federal, $1988 . \quad$ Disponível em: <https://www.planalto.gov.br/ccivil_03/constituicao/constituicao.htm >. Acesso em: $19 \mathrm{dez}$. 2016.

BRASIL. Decreto $\mathrm{n}^{\circ}$ 5.296, de 2 de dezembro de 2004a. Regulamenta as Leis $\mathrm{n}$. 10.048, de 8 de novembro de 2000, que dá prioridade de atendimento às pessoas que especifica, e 10.098, de 19 de dezembro de 2000, que estabelece normas gerais e critérios básicos para a promoção da acessibilidade das pessoas portadoras de deficiência ou com mobilidade reduzida, e dá outras providências. Brasília: Senado Federal, 2004a. Disponível em: <http://www.planalto.gov.br/ccivil_03/_ato2004-2006/2004/decreto/d5296.htm >. Acesso em: 1 ago. 2016.

BRASIL. Lei no 9.394, de 20 de dezembro de 1996. Estabelece as Diretrizes e Bases da Educação Nacional. Brasília: Senado Federal, 1996. Disponível em: <https://www.planalto.gov.br/ccivil_03/Leis/L9394.htm >. Acesso em: 30 nov. 2016.

BRASIL. Lei $\mathrm{n}^{\circ}$ 13.409, de 28 de dezembro de 2016. Altera a Lei no 12.711, de 29 de agosto de 2012, para dispor sobre a reserva de vagas para pessoas com deficiência nos cursos técnico de nível médio e superior das instituições federais de ensino. Brasília, 2016. Disponível em: <http://www2.camara.leg.br/legin/fed/lei/2016/lei-13409-28-dezembro-2016-784149publicacaooriginal-151756-pl.html >. Acesso em 15 jan. 2017.

BRASIL. Ministério da Educação. SEESP. Política Nacional de Educação Especial na Perspectiva da Educação Inclusiva. Brasília, DF: MEC, 2008b.

BRASIL. Subsecretaria Nacional de Promoção dos Direitos da Pessoa com Deficiência. Comitê de Ajudas Técnicas. Tecnologia Assistiva. Brasília: CORDE, 2009b. Disponível em: <http://www.pessoacomdeficiencia.gov.br/app/sites/default/files/publicacoes/livrotecnologia-assistiva.pdf >. Acesso em: 20 jan. 2017. 
CONTE, Elaine; OURIQUE, Maiane Liana Hatschbach; BASEGIO, Antonio Carlos. Tecnologia assistiva, direitos humanos e educação inclusiva: uma nova sensibilidade. Educação em Revista, Belo Horizonte, n. 33, e163600, 2017.

DECLARAÇÃO de Salamanca. 1994.10 Disponível em:<http://portal.mec.gov.br/seesp/arquivos/pdf/salamanca.pdf >. Acesso em: 10 jan. 2017.

DECLARAÇÃO mundial sobre educação para todos: satisfação das necessidades básicas de aprendizagem, Jomtien, 1990. UNESCO, 1998. Disponível em: <http://unesdoc.unesco.org/images/0008/000862/086291por.pdf >. Acesso em: 20 fev. 2018.

EBC AGÊNCIA BRASIL. Falhas da educação inclusiva ainda deixam $\mathbf{1 4 0}$ mil jovens fora das escolas. 2014. Disponível em: <http://agenciabrasil.ebc.com.br/educacao/noticia/201409/falhas-da-educacao-inclusiva-ainda-deixam-140-mil-jovens-fora-das-escolas >. Acesso em: 07 fev. 2018.

FIALHO, Janaina; SILVA, Daiane de Oliveira. Informação e conhecimento acessíveis aos deficientes visuais nas bibliotecas universitárias. Perspectivas em Ciência da Informação, Belo Horizonte, v. 17, n. 1, p. 153-168, jan./mar. 2012.

INEP. Censo escolar da educação básica 2016: notas estatísticas. Brasília: INEP, 2017. Disponível em:

<http://download.inep.gov.br/educacao_basica/censo_escolar/notas_estatisticas/2017/notas _estatisticas_censo_escolar_da_educacao_basica_2016.pdf >. Acesso em: 19 mai. 2017.

KASSAR, Mônica de Carvalho Magalhães. Educação especial na perspectiva da educação inclusiva: desafios da implantação de uma política nacional. Educar em Revista, Curitiba, n. 41, p. 61-79, jul./set. 2011. Disponível em: <http://www.scielo.br/pdf/er/n41/05.pdf >. Acesso em: 02 mai. 2018.

MALHEIROS, Tania Milca de Carvalho. Necessidade de informação do usuário com deficiência visual: um estudo de caso da Biblioteca Digital e Sonora da Universidade de Brasília. 2013. 305 f., il. Dissertação (Mestrado em Ciência da Informação)—Universidade de Brasília, Brasília, 2013.

MAZZONI, Alberto Angel et al. Aspectos que interferem na construção da acessibilidade em bibliotecas universitárias. Ciência da Informação, Brasília, v. 30, n. 2, p. 29-34, maio/ago. 2001.

MELO, Amanda Meincke; COSTA, Jean Braz da; SOARES, Sílvia C. de Matos. Tecnologias assistivas. In: PUPO, Deise Tallarico; MELO, Amanda Meincke; FERRÉS, Sofia Pérez (Org.). Acessibilidade: discurso e prática no cotidiano das bibliotecas. Campinas, SP: Unicamp, 2006.

MENDES, Enicéia Gonçalves. A radicalização do debate sobre inclusão escolar no Brasil. Revista Brasileira de Educação, v. 11, n. 33, set./dez. 2006.

MENDES, Enicéia Gonçalves. Breve histórico da educação especial no Brasil. Revista Educación y Pedagogía, v. 22, n. 57, mayo-agosto, 2010.

MUSTAFA, Patrícia Soraya. Estado capitalista brasileiro: análise dos direitos sociais em tempos de ortodoxia neoliberal. Revista Katálysis, Florianópolis, v. 22, n. 1, jan./abr. 2019. 
OLIVEIRA, Gabriella Domingos de. Bibliotecas e Bibliotecários em busca de acessibilidade. 2013, 56 f. Monografia (Dissertação Biblioteconomia) - Departamento de Ciência da Informação, Universidade Federal do Rio Grande do Norte, 2013. Disponível em: $<$ https://monografias.ufrn.br/jspui/bitstream/1/722/1/GabriellaDO_Monografia.pdf >. Acesso em: 15 mai. 2018.

PADILHA, Caio Augusto Toledo. Educação e inclusão no Brasil (1985-2010). 2014. 342 f. Dissertação (Mestrado em Educação) - Faculdade de Educação, Universidade Estadual de Campinas, Campinas, 2014.

PUPO, Deise Tallarico. Laboratório de acessibilidade. In: PUPO, Deise Tallarico; MELO, Amanda Meincke; FERRÉS, Sofia Pérez (Org.). Acessibilidade: discurso e prática no cotidiano das bibliotecas. Campinas, SP: Unicamp, 2006b.

PUPO, Deise Tallarico; MARTINS, Valéria dos Santos Gouveia. Construção de parâmetros para implantação de bibliotecas acessíveis. Revista Gestão \& Conexões, v. 3, n. 1, jan./jun. 2014. Disponível em: <http://www.periodicos.ufes.br/ppgadm/article/view/5049/5567 >. Acesso em: 29 jun. 2019.

SASSAKI, Romeu Kazumi. Inclusão: construindo uma sociedade para todos. 7. ed. Rio de Janeiro: WVA, 2006.

SONZA, Andréa Poletto. Ambientes virtuais acessíveis sob a perspectiva de usuários com limitação visual. 2008. 313f. Tese (Doutorado em Informática na Educação) - Programa de PósGraduação em Informática na Educação, Universidade Federal do Rio Grande do Sul, Porto Alegre, $2008 . \quad$ Disponível em: <https://www.lume.ufrgs.br/bitstream/handle/10183/14661/000666392.pdf?sequence=1\&isA llowed=y >. Acesso em: 29 jun. 2019. 